\title{
The Cultivating Strategies of Pre-Service Teachers' Informatization Teaching Ability Oriented to Wisdom Generation
}

\author{
https://doi.org/10.3991/ijet.v16i06.17089 \\ Li Liu, Chizhu Ma ${ }^{(\varpi)}$ \\ Shandong Normal University, Jinan, China \\ machizhul126. com \\ Yongchao Wang \\ Hebei Normal University, Shijiazhuang, China
}

\begin{abstract}
The widespread appearance of smart classrooms in basic education puts forward higher requirements for teachers' informatization teaching ability. The educational goal of pre-service teachers is changed from "knowledge mastering" to "wisdom generation", that is, to cultivate their wisdom-generating informatization teaching ability in the informatization education classroom to solve problems effectively. The purpose of this study is to propose cultivating strategies along the theoretical path of wisdom generation, and to test the effectiveness of the cultivating strategies in pre-service teachers' classroom teaching. This research was conducted at Shandong Normal University, and a total of 272 students (pre-service teachers) participated. Through 18 weeks of teaching practice, the results show that pre-service teachers' informatization teaching awareness, knowledge, skills and high-level abilities have generally improved.
\end{abstract}

Keywords - Wisdom, pre-service teachers, informatization teaching ability, wisdom generation, cultivating strategy

\section{Introduction}

The rapid development of a new generation of information technology, such as artificial intelligence, big data, and blockchain, has further stimulated the revolutionary impact of information technology on education, and promoted a new stage of innovation and integration of information technology into education and teaching. The new generation of information technology not only breaks the school walls, builds an smart teaching environment, and makes education more open and shared, but it also changes the way of teaching information dissemination and storage, making teaching content and resources more abundant. More importantly, information technology acts on the teaching process, changing the teaching mode of teachers and the learning style of students, and truly realizes the renewal of educational concepts, the reform of teaching mode and the reconstruction of the educational system. These put forward 
new requirements for teachers' informatization teaching ability. To this end, China has issued the "Educational Informationization 2.0 Action Plan" policy, which states clearly the action goals for the improvement of teachers' informatization teaching level and students' information literacy [1]. Therefore, in our country's teacher education system, it is very important and urgent to improve teachers' informatization teaching ability.

The continuous advancement of education informatization has accelerated the process of basic education reform. In the process of close integration of information technology into education and teaching, a new education pattern represented by smart classroom and flipped classroom has been born [2]. This requires teachers with high informatization teaching ability to adapt to the new education style. Informatization teaching ability is embodied not only in the application of information technology to optimize teaching skills, but also in the formation of the wisdom of using information technology to innovate teaching, to solve complex teaching problems, and to deal with the challenges of a new round of information technology to educational concepts, educational methods and educational ecology. At the same time, the teaching goal of wisdom generation in basic education smart classroom urgently needs pre-service teachers' teaching philosophy to shift from "knowledge mastering" to "wisdom generation" in order to be competent for smart classroom teaching in basic education. Therefore, exploring the cultivating strategies of pre-service teachers' information teaching ability has become a new topic.

The structure of this study is as follows. First of all, the literature reviewing about informatization teaching ability and wisdom education are presented. Then, with the support of relevant theoretical foundations, the theoretical framework of this research, that is, the theoretical path of wisdom generation, is formed. Subsequently, the research method and cultivating strategies are reported, and the data is processed and analyzed. Finally, the results and limitations of this study are discussed.

\section{$2 \quad$ Literature Review}

\subsection{Informatization teaching ability}

Informatization teaching ability, also known as information and communication technology, is the core teaching ability of teachers in informatization teaching. It is the use of information technology to support teaching and learning, and its purpose is to realize technology to promote learning [3][4]. The formation of informatization teaching ability includes not only teachers' post-service training, but also teachers' pre-service informatization curriculum education [5]. Therefore, the informatization teaching ability of pre-service teachers has also received extensive attention from researchers. The research topics focus on the status quo, influencing factors, attitudes of use, evaluation system of pre-service teachers' informatization teaching ability [6][7][8], and how to cultivate and improve strategies in classroom education. Special attention is paid to the kind of informatization teaching ability and how to cultivate the pre-service teachers' ability in classroom teaching. Lim designs information edu- 
cation courses from the perspectives of curriculum resource development, extracurricular learning design, and innovative teaching methods, etc., to improve the information technology education knowledge and skills of pre-service teachers [9]. From the perspective of smart classroom, Di explores how a technologically rich teaching environment can promote learners to carry out high-level thinking activities [10]. Papadakis discusses from the pre-service teachers' attitudes towards information technology, based on TAM [11][12]. There are also researches on improving teachers' informatization teaching ability with the help of the theoretical framework of TPACK.

Through literature review, it is found that the existing researches on pre-service teacher education are more focused on the acquisition of informatization teaching knowledge and skills; the cultivating model is simple; there are fewer internship opportunities, and the lack of attention and application of new technologies, only the initial stage of "application" and "integration" in education and teaching [13][14]. In the era of educational informatization 2.0 that is transforming to "integrated innovation", it should be more important for teachers to understand the essence of informatization teaching methods, to apply information technology to reflecting on teaching, to use knowledge skills effectively to generate wisdom, to solve teaching problems flexibly, and eventually to adapt to the complex and changing information teaching environment. The pre-service education curriculum cultivating system of educational informatization is lagging behind and does not satisfy the actual demand for teachers' informatization teaching ability in the new era. Therefore, the construction of a new cultivating model in the pre-service education classroom has become an important issue.

\section{$2.2 \quad$ Wisdom education}

The development of students' wisdom is the ancient idea of education and the ultimate goal of education. As Whitehead once pointed out: "The whole purpose of education is to make people wise. This is the core of all education." American psychologist Sternberg believes that wisdom is mature and prudent judgment, foresight in practical situations, and the use of experience in handling complex situations. The explicit representation of wisdom is a complex of high-level abilities, problem-solving ability and creative ability etc., specifically manifested in individual criticality.[15]. With the continuous development of education informatization, the smart environment constructed by the new generation of information technology has become an important support for the realization of wisdom education, which is also a manifestation of the era of wisdom education. Zhu pointed out that wisdom education is to build a learning environment that integrates different technologies, allowing teachers to implement efficient teaching methods, allowing learners to obtain personalized learning services, and ultimately improving learners' creativity, problem-solving ability and other highlevel abilities (i.e., wisdom) [16]. Scholars at home and abroad have carried out extensive researches on wisdom education, mainly focusing on the key technical support, system framework construction, smart teaching resources, and exploration of implementation paths [17][18][19]. The U.S. Department of Education issued "Change American Education: Technology-enhanced learning-American National Educational 
Technology Plan 2010", which proposes a learning model for the 21 st century from the five elements of learning, evaluation, teaching, facilities and performance to provide a basis for cultivating talents.

To sum up, the existing researches on informatization teaching ability lack the exploration to enable pre-service teachers to effectively apply knowledge and generate wisdom. This research draws on Sternberg's point of view and believes that wisdom is based on knowledge, and individuals can solve complex problems novely and efficiently through practice and careful judgment. Therefore, from the perspective of wisdom generation, the pre-service teachers' informatization teaching ability is cultivated. In the pre-service education classroom, the focus has been shifted from the cultivation of informatization knowledge to the cultivation of informatization ability. Starting from the transformation of classroom teaching concepts, teaching methods and teaching processes, pre-service teachers are transformed from a one-dimensional "knowledgeable person" into a "wise person" with high-level capabilities. This is not only the embodiment of the epochal nature of education, but also the eternal pursuit of education: from "knowledge mastering" to "wisdom generation", to meet the needs of teachers' informatization teaching ability in the information 2.0 era.

\section{Theoretical Framework}

This research is to cultivate the informatization teaching ability of pre-service teachers in the pre-service education classroom along the path of wisdom generation, so the theoretical path of wisdom generation is the theoretical framework. First, under the guidance of generative theory, the connotation of wisdom generation is derived from the connotation of wisdom. Then, according to Sternberg's triple intelligence theory, the three processes of wisdom generation are sorted out. Finally, combining the research results of the Chinese philosopher Feng, and based on the relevant literature, the study clarifies the theoretical path of wisdom generation.

\subsection{Connotation of wisdom generation}

Generation refers to the formation of new connections between unrelated ideas in the mind. It is a process in which knowledge is processed, transformed, and integrated to form new thinking products [14]. This kind of process is an "insight" in solving new problems. As a unique learning process, generation is conditional. From the perspective of internal conditions, only the knowledge to establish associations can be found in the mind; from the perspective of external conditions, the occurrence of generation must be stimulated by a certain external situation, which often occurs in solving problems with poor structure. From this perspective, the generation of wisdom refers to the stimulation of external complex problematic situations based on knowledge. Self-knowledge undergoes processing and transformation, integration and coordination, and meaning construction, so as to solve problems creatively and skillfully, and then obtain high-level thinking processes such as problem solving, critical thinking, and creativity. 


\subsection{The process of wisdom generation}

Wisdom generation is the development process of individual subjective thinking, the leap from low-level thinking to high-level thinking, a complex thinking activity. Sternberg demonstrates the connotation and essence of wisdom from three perspectives: composition, context, and experience [15]. He also describes the three processes of generating wisdom: the process of knowledge accumulation, the process of participation in practical situations, and the process of reflection forming experience.

Wisdom generation is the process of knowledge accumulation: Knowledge and wisdom have complex connections and differences. Knowledge is the source of the generation of wisdom, and the "qualitative change" of wisdom generation is based on the "quantitative change" of knowledge. Wisdom generation is the process of transforming and integrating declarative knowledge, procedural knowledge, or strategic knowledge based on knowledge acquisition, through subjective analysis and internalization, to solve complex problematic situations.

Wisdom generation is the process of participation in practical situations: "Embodied" cognition points out that only by turning to experience and practice can we have real cognition, wisdom and insight [16]. Wisdom is manifested as higher-order thinking ability. Wisdom generation must also be a process of deep learning and a process of "doing" learning. Max points out that education needs to turn to practice[17].Only true practical activities will have complex problems, will stimulate individuals to mobilize knowledge to solve problems, and form high-level abilities, namely wisdom, after solving problems. Therefore, wisdom generation must be a participatory process of practical situations.

Wisdom generation is the process of rational reflection-forming experience: The one-way accumulation of knowledge without reflection is at best a repetitive and mechanical quantitative accumulation. The extent to which knowledge promotes the generation of wisdom depends on the depth of understanding based on reflective thinking. The individual reflects and reconstructs an experience to form generated experience; the generated experience provides the basis for the next re-experience, from which new experience is generated. The process of rationally reflecting on an experience to form generated experience, reorganizing and transforming experience is the process of deep learning and generating wisdom.

\subsection{Theoretical path of wisdom generation}

From the three processes of the generation of wisdom, it can be concluded that the generation of wisdom is to obtain knowledge first, then practice and apply, and then rationally reflect to generate wisdom. Our contemporary philosopher Feng believes that the generation of wisdom includes two leaps in the cognitive process, namely, the leap from ignorance to knowledge and the leap from knowledge to wisdom [18]. This corresponds to the three processes of wisdom generation. The transition from ignorance to knowledge is the process of knowledge construction, including knowledge acquisition and active internalization; the transition from knowledge to wisdom is the 
process of meaning construction, including practical application and rational reflection, as shown in Figure 1.

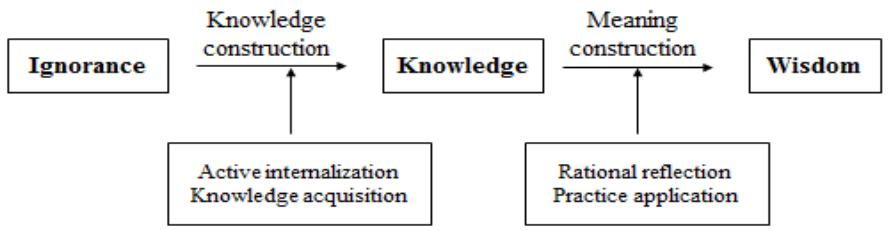

Fig. 1. Theoretical path of wisdom generation

The first leap is a process in which students acquire knowledge and actively internalize it. They first have a perceptual understanding of different types of knowledge, and then actively establish a connection with existing knowledge with the help of external conditions, form structured knowledge through internal assimilation and balance, and then complete knowledge construction. This stage is the low-level thinking process to acquire knowledge, memory, and skill operation. The second leap is based on experience and reflection, through complex internal mental processing such as practical application and rational reflection, and finally solves real problems ingeniously, accurately and quickly. This stage is the process of deep processing of thinking and meaning construction, and the process of forming high-level thinking qualities such as critical thinking, creativity and problem-solving skills. In the two leaps of wisdom generation, metacognitive ability and communication and cooperation ability play an important role in coordination and balance. Among them, metacognitive ability is not only the result of wisdom generation, but also plays a regulatory role in the process of wisdom generation. The collision of ideas of the subject in communication and cooperation promotes the development of individual metacognitive ability. Therefore, metacognitive ability, communication and collaboration ability complement and penetrate each other in the process of wisdom generation.

\section{$4 \quad$ Methodology}

The purpose of this research is to explore whether the use of cultivating strategies in pre-service education classrooms enables them to have the informatization teaching ability oriented to wisdom generation. Therefore, this study adopts a quasiexperimental research method, using the "Questionnaire Star" platform and SPSS to collect and process data.

\subsection{Research design}

The sample comes from 272 students (pre-service teachers) who participated in the "Modern Educational Technology" course of Shandong Normal University. Before the start of the semester, students were divided into two classes evenly. One class, the experimental class, was taught by the cultivating strategies proposed in this study; the 
other class was the control class. The teaching implementation time was from February 24 to June 28, 2020, a total of 18 weeks. Both classes were taught in the form of teamwork, with each group of members (3-4). The control class adopted traditional teaching methods; the experimental class used the "Superstar Learning Link" platform to teach in accordance with the flipped classroom teaching model.

The teaching process of the experimental class was as follows: the first 9 weeks were spent learning the theoretical knowledge of informatization. Before the class, students used self-learning task lists and topic posts to conduct online learning in the form of mobile learning. After that, the members of the group completed the homework independently, and the group leader summarized the questions; the teacher explained the important and difficult knowledge and conducted question-answering. When the course was over, they took a test. The next 9 weeks were for research study under the guidance of teachers. Students checked the practical tasks in the learning platform before class, and completed the tasks collaboratively in the group. In the class, the results were reported in the group as a unit, and at the same time, the evaluation within and between groups was carried out. After class, students modified and improved the results until a satisfactory research report was formed.

\subsection{Research instruments}

Along the path of wisdom generation, the connotation of the informatization teaching ability for wisdom generation also includes two leaps in the cognitive process. The first leap, from ignorance to knowledge, is the process of acquiring informatization teaching awareness, informatization teaching knowledge, and informatization teaching skills; the second leap is to impart informatization teaching knowledge and skills through field practice and rational reflection in real teaching. Wisdom generated in "learning by doing" is characterized by the formation of a complex of high-level capabilities after solving complex problems. It is a leap from knowledge to wisdom.

On this basis, the measurement tool of this research is formed: the informationbased teaching ability scale for wisdom generation, which contains four dimensions: informatization teaching awareness (YS), informatization teaching knowledge (ZS), informatization teaching skills (JN), and high-level capabilities (GJ). Among them, evaluated by the content standards in the Chinese "Educational Technology Ability Standards for Primary and Secondary School Teachers", the informatization teaching awareness (5 items), informatization teaching knowledge (7 items), and informatization teaching skills (13items) - three-dimensional indicator content-are obtained. Reference is also drawn from the 5C scale of Huang, to obtain the index content included in the high-level ability dimension.

This measurement tool used the Likert 5-point scale, which was divided from "strongly disagree" (1point) to "strongly agree" (5 points). The data obtained in the mid-semester test was imported into SPSS 21.0 for reliability and validity testing. The results showed that Cronbach's $\alpha$ was $0.956>0.9$, which indicated that the internal consistency of the questionnaire was high and the reliability was good. This questionnaire was compiled collectively by all teachers of the "Modern Educational Technology" course and revised and improved by two experts, thus ensuring the validity of 
the content of the scale. In order to further test the structural validity of the scale, after calculating the KMO value and the Bartlett sphere test, a total of 4 components were extracted using principal component analysis, and the factor loading of each component was $0.491-0.655,0.508-0.590,0.248-0.367,0.512-0.792$, which proved the structural validity was not ideal. The ZS1 with the smallest factor loading was deleted. After re-run, it was found that the total variance explanation increased from $65.347 \%$ to $65.626 \%$, and the factor loading of each component was between $0.304-0.796$, indicating that the scale had good structural validity [22].

\section{$5 \quad$ Cultivating Strategy}

Some scholars point out that the current education's attention to core vocabulary such as "experience, reflection, construction, and meaning" shows exactly the orientation of "wisdom generation"[23]. Based on this, this research combines the theoretical path of wisdom generation and proposes cultivating strategies supported by the smart environment, which mainly include cognitive strategy, practical strategy, evaluation strategy, interaction strategy and metacognitive strategy. It is worth pointing out that these strategies are a holistic strategy proposed to integrate the two cognitive leaps. It is not a simple accumulation, but is interconnected and permeates each other.

\subsection{Cognitive strategy}

Cognitive strategies include "question-driven, task guidance, and answering questions." Problem-based teaching triggers students to actively discover and explore knowledge. The task-guided teaching makes students change from passive learning to active learning, and from knowledge learning to problem learning. At the same time, the question-answering activities carried out in the form of a team help students construct knowledge collaboratively and provide students with a learning context for wisdom training. Curriculum learning has become a wisdom process of independent inquiry, critical reconstruction, and active internalization among individuals. In the process of completing the leap from ignorance to knowledge, critical thinking, communication and collaboration skills have also been cultivated.

\subsection{Practical strategy}

The practical strategies mainly include "designing teaching plans, making demonstration courseware, analyzing micro-class cases, and making knowledge-point microclasses". These practical activities enable students to select and use information-based teaching knowledge with the help of real situations and transform it into teaching experience. Through the fusion of theoretical knowledge and educational context, on the one hand, students experience the true process of effectively imparting knowledge and complete the meaning construction of knowledge; On the other hand, in the continuous reflection, modification and improvement, the students' self-cognition structure has been transformed and enriched, which directly contributes to the high-level quali- 
ties such as metacognitive ability, problem solving ability, communication and collaboration.

\subsection{Evaluation strategy of multi-subject}

Effective evaluation is of great significance for learning, motivating, guiding and diagnosing [24]. It is an important means to awaken students' potential, regulate the learning process, and stimulate wisdom. This research proposes multi-subject evaluation methods such as self-evaluation, mutual evaluation, and other evaluation, as well as multiple evaluation methods that combine process evaluation and summative evaluation. The multi-subject evaluation method not only makes the evaluation results more comprehensive and objective, but also enables students to make self-recognition deepen their knowledge in the cycle of evaluation, reflection, and optimization, and acquire critical thinking, communication and collaboration skills. Multiple evaluation methods help to stimulate students' enthusiasm for knowledge and contribution in the process of independent exploration and teamwork.

\section{$5.4 \quad$ Interaction strategy}

The interaction mainly includes the interaction between students and students, the interaction between students and teachers, and the interaction between students and learning resources [25]. This study adopts the form of teamwork learning, which can not only effectively restrain the inertia of individual thinking, but also exert the effect of collective construction [26], and realize the deepening and expansion of thinking through mutual debate and communication among students. Moreover, in a harmonious and shared atmosphere, individual cognition is stimulated. Through continuous communication and explanation, reflection and criticism, reconstruction and other thinking activities, students experience the tortuous and rising process of thinking.

\subsection{Metacognitive strategy}

Metacognition is the ability of individuals to recognize, plan, monitor and regulate themselves during the cognitive process. Metacognitive strategies always appear at the same time with other cultivating strategies to realize the generation of wisdom together. On the one hand, by issuing learning task lists and formulating hierarchical learning tasks, students can plan independently, regulate the learning process, and form strategic knowledge, so as to cultivate their metacognitive ability. On the other hand, the permanent recording and preservation of learning process data in the smart learning environment enables students to conduct self-summary and reflection by viewing and reviewing their own cognitive processes, and to improve their selfmonitoring ability. 


\section{$6 \quad$ Results}

This study conducts descriptive analysis and independent sample t-test on the data. The specific results are described below.

\section{- The dimension of informatization teaching awareness}

The average value of informatization teaching awareness is the highest, between 4.34 and 4.44, as shown in Table 1, reaching the level of "agreement". It shows that the information technology application awareness and attitude of pre-service teachers have met the requirements. This also shows that through the cultivating strategies of this research, pre-service teachers hold a positive attitude towards the use of information technology to support their own learning, and then to recognize the effect of information teaching. At the same time, they have the willingness to integrate information technology into teaching actively and consciously, and they have strengthened their belief in using information technology to support their professional development and improve their teaching ability in future teaching. Further analysis finds that preservice teachers have the highest score $(\mathrm{M}=4.5, \quad \mathrm{SD}=0.543)$ for YS3: "I can continuously pay attention to the development of new technologies and actively share information-based teaching experience". This is also consistent with Du's research conclusions, indicating that pre-service teachers are willing to accept new technology, and apply it to their own teaching, and are willing to share with others [27].

Table 1. Analysis results of informatization teaching awareness

\begin{tabular}{|c|c|c|c|c|c|}
\hline Dimension & Item & minimum & max & mean & Standard deviation \\
\hline \multirow{4}{*}{ Awareness } & YS1 & 2 & 5 & 4.34 & .635 \\
\cline { 2 - 6 } & YS2 & 2 & 5 & 4.44 & .580 \\
\cline { 2 - 6 } & YS3 & 3 & 5 & 4.50 & .543 \\
\cline { 2 - 6 } & YS4 & 3 & 5 & 4.35 & .600 \\
\cline { 2 - 6 } & YS5 & 2 & 5 & 4.39 & .615 \\
\hline
\end{tabular}

\section{- The dimension of informatization teaching knowledge}

The average value of informatization teaching knowledge is between 3.59 and 3.88 , as shown in Table 2, which has not yet reached the level of "agreement". However, the average score for all questions is more than $50 \%$ of the total score, which also shows that through the implementation of cognitive strategies such as "problemdriven, task guidance, and answering questions", pre-service teachers are wellequipped. Learner-centered and problem-based teaching can stimulate students' enthusiasm, enable them to learn actively, and then actively construct knowledge [28]. Further analysis finds that pre-service teachers have the lowest scores $(M=3.59$, $\mathrm{SD}=0.763$ ) for informatization education policy knowledge, while the ZS3: "I have the basic knowledge of teaching system design" has the highest scores ( $M=3.88$, $\mathrm{SD}=0.620$ ) . It shows that the practical activities of "writing the teaching system design plan" can deepen the mastery and understanding of the knowledge points, once 
again confirming the effectiveness of problem-based teaching for knowledge acquisition [29].

Table 2. Analysis results of informatization teaching knowledge

\begin{tabular}{|c|c|c|c|c|c|}
\hline Dimension & Item & minimum & max & mean & Standard deviation \\
\hline \multirow{5}{*}{ Knowledge } & ZS2 & 2 & 5 & 3.65 & .709 \\
\cline { 2 - 6 } & ZS3 & 2 & 5 & 3.88 & .620 \\
\cline { 2 - 6 } & ZS4 & 2 & 5 & 3.76 & .657 \\
\cline { 2 - 6 } & ZS5 & 2 & 5 & 3.77 & .655 \\
\cline { 2 - 6 } & ZS6 & 2 & 5 & 3.83 & .608 \\
\cline { 2 - 6 } & ZS7 & 2 & 5 & 3.59 & .763 \\
\hline
\end{tabular}

\section{- The dimension of informatization teaching skills}

The average value of informatization teaching skills fluctuates greatly, ranging from 3.47 to 4.33, as shown in Table 3. Among them, JN1: "I can operate various hardware devices in the smart teaching environment" has the lowest score $(M=3.47$ , $\mathrm{SD}=0.763$ ), which may be related to the impact of COVID-19 this semester. Although online teaching pays attention to the provision of relevant hardware facilities, based on specific case analysis, pre-service teachers have an overall perception of the smart teaching environment. However, virtual immersion and on-site interaction can enable pre-service teachers to better master their skills [30]. Without on-site perception and interaction in this study, the experience of pre-service teachers still stays in their heads. This also confirms the possibility that virtual reality will transform education and teaching. The average score of each topic is more than $50 \%$ of the total score, which proves the effectiveness of the cultivating strategy in this study. It shows that through the implementation of practical activities, pre-service teachers can skillfully use information technology to support teaching and reasonably design and use teaching resources to serve teaching.

Table 3. Analysis results of informatization teaching skills

\begin{tabular}{|c|c|c|c|c|c|}
\hline Dimension & Item & minimum & max & mean & Standard deviation \\
\hline \multirow{5}{*}{} & JN1 & 1 & 5 & 3.47 & .763 \\
\cline { 2 - 6 } & JN2 & 1 & 5 & 3.71 & .693 \\
\cline { 2 - 6 } & JN3 & 1 & 5 & 3.87 & .644 \\
\cline { 2 - 6 } & JN4 & 2 & 5 & 3.94 & .582 \\
\cline { 2 - 6 } & JN5 & 1 & 5 & 3.77 & .699 \\
\cline { 2 - 6 } & JN6 & 2 & 5 & 3.86 & .656 \\
\cline { 2 - 6 } & JN7 & 3 & 5 & 4.33 & .583 \\
\cline { 2 - 6 } & JN8 & 2 & 5 & 3.97 & .569 \\
\cline { 2 - 6 } & JN9 & 2 & 5 & 3.80 & .685 \\
\cline { 2 - 6 } & JN10 & 2 & 5 & 3.91 & .607 \\
\cline { 2 - 6 } & JN11 & 2 & 5 & 3.87 & .663 \\
\cline { 2 - 6 } & JN12 & 2 & 5 & 3.89 & .631 \\
\cline { 2 - 6 } & JN13 & 2 & 5 & 4.00 & .560 \\
\hline
\end{tabular}




\section{- The dimension of higher order abilities}

In order to test whether the strategy proposed in this study has improved the highlevel ability of pre-service teachers, an independent sample t-test was performed on the five measurement dimensions of high-level ability. The results are shown in Table 4. There are significant differences in the dimensions of communication and collaboration, problem solving, metacognition, critical thinking, and creative ability $(\operatorname{sig}<0.05)$. This fully shows that through the comprehensive application of the cultivating strategies proposed in this research and mobilizing their learning initiative [31], the high-level thinking level of pre-service teachers has been significantly improved, and the goal of "turning knowledge into wisdom" has been achieved. Further analysis finds that the score of collaborative communication ability is the highest $(M=4.33$, $\mathrm{SD}=0.331)$, and the score of creativity is the lowest $(\mathrm{M}=3.81, \mathrm{SD}=0.406)$, indicating that the teamwork learning method in teaching practice greatly improves the preservice teachers' communication and interaction, collaboration and communication skills. Although creative ability has improved significantly, its cultivating process is not accomplished overnight; it requires long-term accumulation and persistence [32].

Table 4. Analysis results of high-order abilities

\begin{tabular}{|c|c|c|c|c|c|c|c|}
\hline \multirow{3}{*}{$\begin{array}{l}\text { Matching } \\
\text { dimension }\end{array}$} & \multicolumn{2}{|c|}{$\begin{array}{l}\text { Levine Variance } \\
\text { Equivalence Test }\end{array}$} & \multicolumn{5}{|c|}{ Mean equivalence $T$ test } \\
\hline & \multirow[t]{2}{*}{$\boldsymbol{F}$} & \multirow{2}{*}{$\begin{array}{l}\text { Signifi- } \\
\text { cance }\end{array}$} & \multirow{2}{*}{$t$} & \multirow{2}{*}{$\begin{array}{l}\text { Significance } \\
\text { (double tails) }\end{array}$} & \multirow{2}{*}{$\begin{array}{c}\text { Mean } \\
\text { difference }\end{array}$} & \multicolumn{2}{|c|}{$\begin{array}{c}\text { The difference is } 95 \% \\
\text { confidence interval }\end{array}$} \\
\hline & & & & & & Lower limit & Upper limit \\
\hline $\begin{array}{l}\text { Communication and } \\
\text { collaboration }\end{array}$ & & & -32.616 & .000 & -2.159 & -2.28 & -2.028 \\
\hline Problem solving & 2.167 & .142 & -33.834 & .000 & -2.168 & -2.294 & -2.041 \\
\hline Metacognitive & & & -21.859 & .000 & -1.650 & -1.799 & -1.502 \\
\hline Critical thinking & .074 & .786 & -23.043 & .000 & -1.622 & -1.761 & -1.483 \\
\hline Creative ability & 4.743 & .03 & -27.334 & .000 & -1.528 & -1.638 & -1.418 \\
\hline
\end{tabular}

\section{Conclusion}

Wisdom is the eternal pursuit of mankind's self-improvement and the eternal pursuit of education. The development of students' wisdom is the basic orientation of contemporary education reform and the return of contemporary educational value. In order to meet the demands of the era of education informatization 2.0, the main purpose of this research is to add high-level capabilities (i.e., wisdom) that adapt to the rapid development of basic education information technology, to use information technology to solve complex teaching problems on the basis of existing capabilities, and to discuss the effectiveness of cultivating strategies. The results of the study show that the average value of pre-service teachers' informatization teaching awareness, knowledge, and skills have been significantly improved, especially their high-level abilities. 


\section{Limitation}

The experimental data of this research is analyzed with a university as a sample, and may not be representative of students in other places. Future research should sample from a more diverse population to make research conclusions more universal.

Although the cultivating strategies proposed in this study have realized the "conversion of knowledge into wisdom" for pre-service teachers, the educational practice stage is the experience field for wisdom generation. The complex and changeable practical situation is an opportunity for students to think creatively, reflect on practice, and elevate emotions. The future research direction can take virtual reality technology or educational practice sites as the starting point to explore how to train pre-service teachers to use information technology to experience teaching, reflect on teaching, and form wisdom to solve real teaching problems in real educational situations.

\section{Acknowledgement}

This paper is supported by the key project of Education reform in Shandong Province: "Exploration and Practice of Industry-University-Research Collaborative Training of Applied Innovative Media Talents" (No.: Z2018S041).

\section{References}

[1] Ministry of Education of the People's Republic of China. (2018). Notice of the Ministry of Education on Issuing the "Education Informatization 2.0 Action Plan". http://www.moe. gov.cn/srcsite/A16/s3342/201804/t20180425_334188.html

[2] Zhang, L, Xuan, Y, \& Zhang, H. (2020). Construction and application of spoc-based flipped classroom teaching mode in installation engineering cost curriculum based on obe concept. Computer Applications in Engineering Education. https://doi.org/10.1002/cae. $\underline{22320}$

[3] Gibson, D., Broadley, T., Downie, J., \& Wallet, P. (2018). Evolving learning paradigms: Re-setting baselines and collection methods of information and communication technology in education statistics. Educational Technology \& Society, 21(2), 62-73. https://doi.org/ $10.3403 / 30291930 \mathrm{u}$

[4] Liu, Z., Yin, R. (2014). Connotation and Improvement Path of Teachers' Informationized Teaching Ability [J]. Chinese Journal of Education, (10):31-36. https://doi.org/10.3969/ j.issn.1003-9082.2016.12.212

[5] Liu, H., Wang, Q., Su, Y. (2019). Effects of Project-Based Learning on Teachers' Information Teaching Sustainability and Ability. Sustainability, 11(20): 5795. https://doi.org/ $\underline{10.3390 / \text { su } 11205795}$

[6] Sui, X. H, Zhao, G.D, Wang, J.X. (2020). An Empirical Study on the Influencing Factors of University Teachers' Information-based Teaching Ability -- A Case Study of some Universities in Hunan Province [J]. China's audio-visual education. (05):128-134. https://doi. org/10.3969/j.issn.1006-9860.2020.05.023

[7] Acosta, Rosalba \& Joo Nagata, Jorge \& Martín-García, Antonio \& Martín, Azucena. (2020). Perception of Teachers on Collaborative Tools Knowledge Level Mediated by ICT 
and Their Experience with Students. International Journal of Emerging Technologies in Learning (iJET). 15. 137. https://doi.org/10.3991/ijet.v15i11.13121

[8] Mao, C., Liu, J., Nie, L., \& Zhou, Z. (2018). Does evaluation system cause a rise in instructors' informatization teaching abilities? evidence from chinese universities. Educational Sciences: Theory \& Practice, 18(5), 1907-1921. https://doi.org/10.12738/estp.2018. $\underline{5.090}$

[9] Lim, C. P., Yan, H., \& Xiong, X. (2015). Development of pre-service teachers' information and communication technology (ICT) in education competencies in a mainland chinese university. Educational Media International, 52(1), 15-32. https://doi.org/10.1080/ $\underline{09523987.2015 .1005425}$

[10] Di, W., Dan, X., \& Chun, L. (2019). The effects of learner factors on higher-order thinking in the smart classroom environment. Journal of Computers in Education (the Official Journal of the Global Chinese Society for Computers in Education), 6(4), 483-498. https://doi. org/10.1007/s40692-019-00146-4

[11] Papadakis, S. (2018). Evaluating pre-service teachers' acceptance of mobile devices with regards to their age and gender: a case study in Greece. International Journal of Mobile Learning and Organisation, 12(4), 336-352. https://doi.org/10.1504/ijmlo.2018.10013372

[12] Kalogiannakis, M., \& Papadakis, S. (2017). Pre-service kindergarten teachers acceptance of "ScratchJr" as a tool for learning and teaching computational thinking and Science education. In Proceedings of the 12th Conference of the European Science Education Research Association (ESERA), Research, practice and collaboration in science education (pp. 2125).

[13] Zuo, M.Z., Lu, Q.,Lei, L.H.(2016). Confusion and Breakthrough: Practical Research on Regional Teachers' Information Teaching Ability Training [J]. China Audio-Visual Education, (05):104-111. https://doi.org/10.3969/j.issn.1006-9860.2016.05.017

[14] Ma, C.Z., Wei, Y. J., Wu, D. (2017). A Study on the Construction of educational Technology Competence Training Model for Normal University students [J]. Chinese Audio-visual Education (05):102-110+141. https://doi.org/10.3969/j.issn.1006-9860.2017.05.016

[15] Zhu, Z,T.,Peng, H.C.,Lei, Y.H.(2018). Intelligent Education: The Practice Path of Wisdom Education[J].Open Education Research, 24(04):13-24+42. https://doi.org/10.13966/j.cnki. kfjyyj.2018.04.002

[16] Kristjánsson (2020). An introduction to the special issue on wisdom and moral education. 49(1), 1-8. https://doi.org/10.1080/03057240.2019.1705041

[17] Hao, L. (2019). The research of theoretical construction and effect of preschool wisdom education system in the background of big data. 22(6), 13813-13819. https://doi.org/ $\underline{10.1007 / \mathrm{s} 10586-018-2102-6}$

[18] Liu, X.L., Huang, R.H., (2016). From Knowledge to Wisdom: Wisdom Education from the Perspective of Real Learning[J]. China Audio-visual Education, (03):14-20. https://doi.org/ $\underline{10.3969 / j . i s s n .1006-9860.2016 .03 .003}$

[19] Pang, W.G. (2007). Innovative Learning: Generative Perspective [J]. Contemporary Education Science:6-8. https://doi.org/10.3969/j.issn.1672-2221.2007.05.002

[20] Fang, F. (2013). Educational implications of Sternberg's ternary Intelligence theory. Journal of Changchun University of Science and Technology: Social Science edition (07), 193194. https://doi.org/10.3969/j.issn.1009-1068.2013.07.078

[21] Wu, M.L. (2003). SPSS statistical application practice: questionnaire analysis and applied statistics[M]. Science Press:56-59.

[22] Li, Y., Wang, W., Zhong, S.C. (2017). Research on intelligent Generation Strategies in smart Classroom [J]. Research on Audio-visual Education.38(01):108-114. https://doi. org/10.13811/j.cnki.eer.2017.01.014 
[23] Li, F.Q., Han, X.L. (2017). Construction and Practice of Mixed Teaching Quality Evaluation System [J]. China Audio-Visual Education, (11):108-113. https://doi.org/10. 3969/j.issn.1006-9860.2017.11.016

[24] Wang, Z.J. (2016). Re-analysis of the essence and related concepts of "teaching interaction" in distance education. Audio-visual education research, 37(04):36-41. https://doi. org/10.13811/j.cnki.eer.2016.04.005

[25] Liu, L., Ma, C.Z. (2020). Online emergency teaching design with research-based learning as the core during the epidemic prevention and control period -- A case study of "TV Director" online course [J]. Modern educational technology, 30(06):120-126. https://doi.org/ 10.3969/j.issn.1009-8097.2020.06.018

[26] Du, J., Xu, J., Liu, F., Huang, B., \& Li, Z. (2019). Factors influence kindergarten teachers' emotion management in information technology: A multilevel analysis. The Asia-Pacific Education Researcher, 28(6), 519-530. https://doi.org/10.1007/s40299-019-00452-6

[27] Jian, J.Z., Zhong, Q.Z., \& Yan, L. (2019). Adaptability performance evaluation of university teachers' informatization teaching based on entropy weight bayesian bethod. Paper presented at the 1191-1195. https://doi.org/10.1109/itaic.2019.8785758

[28] Stentoft, D. (2017). From saying to doing interdisciplinary learning: Is problem-based learning the answer? Active Learning in Higher Education, 18(1), 51-61. https://doi.org/ $\underline{10.1177 / 1469787417693510}$

[29] Wang, Y. (2020). Application of Virtual Reality Technique in the Construction of Modular Teaching Resources. International Journal of Emerging Technologies in Learning (iJET). 15. 126. https://doi.org/10.3991/ijet.v15i10.14129

[30] Untari, R., Kamdi, W., Dardiri, A., Hadi, S., \& Nurhadi, D. (2020). The Development and Application of Interactive Multimedia in Project-Based Learning to Enhance Students' Achievement for 2D Animation Making. International Journal Of Emerging Technologies In Learning (IJET), 15(16), pp. 17-30. https://doi.org/10.3991/ijet.v15i16.16521

[31] Suhirman, Suhirman \& Yusuf, Yusuf \& Muliadi, Agus \& Prayogi, Saiful. (2020). The Effect of Problem-Based Learning with Character Emphasis toward Students' Higher-Order Thinking Skills and Characters. International Journal of Emerging Technologies in Learning (iJET). 15. 183. https://doi.org/10.3991/ijet.v15i06.12061

\section{Authors}

Li Liu, was born in April 1990. She is a PhD student at the Faculty of Education, Shandong Normal University in P. R. China. Research interests include Computer Education application.

Yongchao Wang, was born in August 1991. He is a lecturer at College English Department, Hebei Normal University in P. R. China.

Chizhu Ma, corresponding author, was born in November 1966. He is a professor at the School of Journalism and Media, Shandong Normal University in P. R. China. He received his $\mathrm{PhD}$ degree from South China Normal University of Educational Technology in 2006.

Article submitted 2020-07-16. Resubmitted 2020-09-19. Final acceptance 2020-11-04. Final version published as submitted by the authors. 